\title{
Pemanfaatan pekarangan dalam upaya mendukung ketahanan pangan keluarga
}

\author{
Titis Sunanti ${ }^{1}$, Koryna Aviory ${ }^{2 *}$ \\ ${ }^{1}$ Universitas PGRI Yogyakarta, Indonesia, email: sunanti@upy.ac.id \\ 2Universitas PGRI Yogyakarta, Indonesia, email: koryna@upy.ac.id \\ *Koresponden penulis
}

\begin{tabular}{|c|c|}
\hline Info Artikel & Abstract \\
\hline \multirow[t]{3}{*}{$\begin{array}{l}\text { Diajukan: } 28 \text { Feb } 2021 \\
\text { Diterima: } 14 \text { Sept } 2021 \\
\text { Diterbitkan: } 01 \text { Okt } 2021 \\
\text { Keywords: } \\
\text { family food security; } \\
\text { horticulture } \\
\text { Kata Kunci: } \\
\text { ketahanan pangan } \\
\text { keluarga; hortikultura } \\
\text { Lisensi: } \\
\text { cc-by-sa }\end{array}$} & $\begin{array}{l}\text { The food security of households is the ability of a family to meet family } \\
\text { food needs independently. The food security of households can be } \\
\text { strengthened by making use of home yards. This service is an activity } \\
\text { that involves the community in strengthening the food security of } \\
\text { households. This service consists of several activities, such as (1) } \\
\text { promoting planting activities so that residents become motivated; (2) } \\
\text { provide counseling on family food security and its strategies, and (3) } \\
\text { provide training on horticultural cultivation. This activity was carried out } \\
\text { well. The number of residents doing planting activities has increased } \\
\text { by } 75.38 \% \text {. While the results of the citizen questionnaire related to this } \\
\text { service activity showed a good response with a percentage of } 77.6 \% \text {. } \\
\text { The residents hope that the community service activities can be } \\
\text { continued with other types of activities, such as assistance to develop } \\
\text { existing activities in the nursery. }\end{array}$ \\
\hline & Abstrak \\
\hline & $\begin{array}{l}\text { Ketahanan pangan keluarga adalah kemampuan sebuah keluarga } \\
\text { dalam memenuhi kebutuhan pangan keluarga secara mandiri. } \\
\text { Ketahanan pangan keluarga dapat dikuatkan dengan memanfaatkan } \\
\text { lahan pekarangan. Pengabdian ini adalah suatu kegiatan yang } \\
\text { melibatkan masyarakat dalam penguatan ketahanan pangan keluarga } \\
\text { (KPK). Pengabdian ini terdiri dari beberapa kegiatan yaitu: (1) } \\
\text { menggalakkan kegiatan menanam agar warga menjadi termotivasi; } \\
\text { (2) memberi penyuluhan tentang ketahanan pangan keluarga dan } \\
\text { strateginya; dan (3) memberi pelatihan tentang budidaya tanaman } \\
\text { holtikurtura. Kegiatan ini terlaksana dengan baik. Jumlah warga yang } \\
\text { berkegiatan menanam mengalami peningkatan sebesar } 75,38 \% \text {. } \\
\text { Sedangakan hasil angket warga terkait kegiatan pengabdian ini } \\
\text { menunjukkan respon yang baik dengan persentase sebesar } 77,6 \% \text {. } \\
\text { Warga berharap agar kegiatan pengabdian dapat dilanjutkan dengan } \\
\text { jenis kegiatan yang lain seperti pendampingan untuk } \\
\text { mengembangkan kegiatan yang ada dikebun bibit. }\end{array}$ \\
\hline
\end{tabular}

\section{PENDAHULUAN}

Pandemi Covid-19 yang saat ini sedang melanda dunia sangat mempengaruhi perekonomian negara-negara di dunia, tidak terkecuali di Indonesia. Terpuruknya perekonomian menyebabkan daya beli masyarakat menurun. Hal ini sangat dirasakan masyarakat sejak awal Maret 2020 (Wahyono, 2020). Kondisi ini terjadi sejak penetapan wabah Covid-19 sebagai 
pandemi nasional. Kegiatan yang melibatkan banyak orang tidak diijinkan. Kegiatan ekonomi nyaris terhenti. Kerugian Indonesia akibat aktivitas ekonomi yang hilang selama tiga bulan mencapai 316 triliun (Alika, 2020). Sektor ekonomi yang mengalami kelumpuhan adalah sektor yang mengandalkan keramaian, seperti tempat wisata, tempat pertunjukan, transportasi massal, tempat makan, dan penginapan, serta sektor yang bergerak pada bidang jasa, seperti salon, pembersih rumah, ojek, dan lain sebagainya (Hadiwardoyo, 2020).

Salah satu kegiatan ekonomi yang berdampak langsung terhadap kehidupan masyarakat adalah tentang pemenuhan kebutuhan pangan (Masniadi et al., 2020). Pemenuhan kebutuhan pangan selama Covid-19 menjadi terhambat dikarenakan daya beli masyarakat yang menurun, serta tidak tersedianya kebutuhan pangan dipasaran karena transportasi yang terhambat. Ketersediaan pangan akan terjamin jika memiliki sistem ketersediaan pangan yang kuat. Kemandirian pangan dicapai dengan pembangunan ketahanan pangan. Kemandirian ini dapat diwujudkan dengan swasembada pangan yang strategis, akses pangan yang meningkat, serta ketersediaan aneka pangan (Hadi \& Susilowati, 2010).

Selama Covid-19 ketahanan pangan terganggu. Kegiatan produksi, distribusi dan konsumsi pangan juga akan berpengaruh (Hirawan \& Verselita, 2020; UMY, 2020). Apabila kondisi ini tidak segera teratasi maka kebutuhan pangan masyarakat khususnya ditingkat keluarga dapat terganggu. Lambat laun hal ini dapat menyebabkan ketahanan pangan nasional goyah. Ketahahan pangan merupakan kondisi terpenuhinya kebutuhan pangan, baik dari segi jumlah maupun mutunya (Rahmawati, 2012). Ketahanan nasional adalah kemampuan suatu negara dalam memenuhi kebutuhan pangan baik ditingkat wilayah maupun tingkat keluarga. Ketahanan pangan nasional dapat diwujudkan melalui ketahanan pangan keluarga. Dengan adanya ketahanan pangan keluarga maka ketahanan pangan wilayah dan ketahanan pangan nasional akan terwujud (Arida et al., 2015). Kondisi pandemi Covid-19 mengharuskan masyarakat berpikir lebih keras untuk dapat memenuhi kebutuhan keluarga khususnya kebutuhan pangan (Aisyah, 2020; Nasution et al., 2020; Sakharina, 2020). Jika masyarakat mampu meningkatkan produktivitas maka pendapatan rumah tangga akan meningkat (Ediwiyati et al., 2015).

Dusun Sidorejo yang berlokasi di desa Ngestiharjo, kecamatan Kasihan kabupaten Bantul merupakan wilayah dengan kondisi lingkungan yang baik. Kontur tanah yang baik dan ketersediaan air yang sangat melimpah merupakan nilai tambah dari dusun ini. Di dusun ini terdapat sebuah rawa yang airnya dapat dimanfaatkan untuk pengairan sawah disekitarnya. Kandungan tanah yang sangat baik membuat tanaman disekitar rawa tumbuh dengan subur. Potensi ini tentu harus dapat dimanfaatkan untuk kesejahteraan masyarakat sekitar rawa yaitu masyarakat dusun Sidorejo.

Dusun Sidorejo adalah salah satu dusun yang mulai menggiatkan tentang program Ketahanan Pangan Keluarga (KPK). Kegiatan ini diawali dengan dibuatnya sebuah kebun bibit. Kebun bibit ini diprakarsai oleh karang 
taruna dusun tersebut sehingga dinamai dengan kebun bibit Nyawiji Mukti. Penamaan kebun bibit sesuai dengan nama kelompok karang taruna di dusun tersebut. Kebun bibit Nyawiji Mukti saat ini dikelola oleh karang taruna. Kebun bibit ini sudah berdiri hampir dua tahun yang lalu, tepatnya 2019. Kebun bibit ini berada disuatu lahan pekarangan milik warga setempat yang bersedia lahannya dijadikan kebun bibit untuk kepentingan bersama.

Kebun bibit Nyawiji Mukti menyediakan bermacam-macam jenis bibit, mulai dari yang berbentuk biji maupun yang sudah disemai bahkan ada yang sudah mulai berbuah. Berbagai jenis bibit buah dan sayur disediakan di kebun bibit ini. Jenis bibit tanaman holtikultura juga tersedia disana. Bibit-bibit yang ada diperoleh atas kerjasama karang taruna dengan tim pengabdi dari Universitas PGRI Yogyakarta (UPY) tahun 2019. Dengan tersedianya berbagai macam bibit, diharapkan masyarakat dapat menanam salah satu jenis bibit di pekarangan rumah mereka. Tujuan dibuatnya kebun bibit adalah untuk membantu masyarakat agar mudah untuk mendapatkan bibit tanaman dengan harga yang terjangkau. Masyarakat di dusun Sidorejo diharapkan memanfaatkan lahan yang mereka miliki untuk peningkatan produksi pertanian. Salah satunya adalah dengan menanam tanaman holtikultura sehingga dapat digunakan untuk kebutuhan pangan sehari-hari. Dengan adanya kebun bibit ini diharapkan kebutuhan pangan keluarga terpenuhi sehingga akan terwujud ketahanan pangan keluarga. Salah satu indikator kesejahteraan hidup adalah ketersediaan pangan yang menunjang ketahanan pangan (Saliem \& Ariani, 2016).

Hampir satu tahun, sejak diresmikan, kebun bibit Nyawiji Mukti belum dimanfaatkan oleh masyarakat dusun Sidorejo dengan baik. Kebun bibit tersebut telah dikelola oleh karang taruna dengan baik. Masih banyak masyarakat yang belum tertarik untuk membeli bahkan memanfaatkan hasil tanaman dari kebun bibit tersebut. Mereka masih ragu dengan kualitas bibit itu. Selain itu, mereka juga ragu terhadap tingkat keberhasilan penanaman jika mereka mencoba bercocok tanam sendiri. Kurangnya edukasi tentang teknik menanam dan cara merawatnya merupakan salah satu faktor penyebabnya. Masyarakat masih memerlukan pendampingan untuk membangkitkan motivasi, meningkatkan pengetahuan, rasa percaya diri, keberanian untuk menanam.

Berdasarkan hasil observasi dan wawancara beberapa masyarakat di dusun Sidorejo menunjukkan bahwa mereka belum sepenuhnya memanfaatkan lahan pekarangan yang mereka miliki. Hampir setiap rumah di dusun Sidorejo memiliki lahan kosong yang bisa dimanfaatkan dengan baik. Warga masih membeli kebutuhan pangan sehari-hari yang berupa sayur dan buah diwarung atau pasar terdekat. Padahal mereka mempunyai halaman rumah atau pekarangan yang dapat dimanfaatkan. Demikian juga dengan bibit yang ada, belum dimanfaatkan secara maksimal.

Rendahnya pengetahuan tentang pemanfaatan lahan pekarangan menjadi faktor penyebabnya. Mereka berpikir bahwa untuk menanam dibutuhkan lahan yang luas dan hanya untuk jenis tanaman tertentu saja. Mereka belum mengetahui potensi lahan yang mereka miliki agar dapat bermanfaat bagi keluarganya. Terlebih lagi di masa pandemi sekarang ini, 
terdapat pembatasan terhadap aktivitas masyarakat, daya beli masyarakat juga mengalami perubahan. Hal ini bisa menjadi peluang bagi masyarakat untuk meningkatkan produksi pertanian melalui ketahanan pangan. Harapannya masyarakat tidak perlu membeli sayur dan buah di warung lagi tetapi cukup memetik hasil dari kebun mereka. Atau mereka dapat saling tukar menukar hasil kebun untuk mencukupi kebutuhan pangan mereka. Dengan demikian, diharapkan ketahanan pangan di dusun Sidorejo mengalami peningkatan.

Ketahanan pangan dapat terjadi jika jumlah pangan dan kualitas pangan mencukupi bagi masyarakat sehingga aman dikonsumsi masyarakat untuk memenuhi kebutuhan sehari-hari (Saliem \& Ariani, 2016). Dari bibit tanaman yang tersedia di kebun bibit Nyawiji Mukti, bibit tanaman holtikultura berpotensi untuk dapat meningkatkan ketahanan pangan di dusun Sidorejo. Holtikultura merupakan pembudidayaan kebun dengan berbagai jenis tanaman, seperti tanaman hias, sayur, dan buah (Fallis, 2013). Pengetahuan mereka tentang tanaman hortikultura dan cara membudidayakan tanaman holtikultura di lahan pekarangan masih sangat minim. Pemilihan jenis tanaman ini diharapkan mampu memenuhi kebutuhan keluarga terkait dengan ketahanan pangan.

Kegiatan yang mungkin dapat dilakukan pada kegiatan pengabdian ini adalah memotivasi masyarakat agar mau menanam, memberi penyuluhan tentang ketahanan pangan keluarga dan strateginya, serta memberi pelatihan tentang budidaya tanaman holtikurtura. Kegiatan ini diharapkan mampu mewujudkan ketahanan pangan dan akhirnya mampu menguatkan ketahanan pangan keluarga. Tujuan dari kegiatan ini adalah dapat membantu menurunkan pengeluaran keluarga dalam memenuhi kebutuhan pangan dengan memproduksi sayur dan buah sendiri.

\section{METODE PELAKSANAAN}

Tahapan awal kegiatan yang dilakukan yaitu observasi. Observasi dilakukan untuk melihat kebutuhan masyarakat di dusun Sidorejo terkait dengan kebutuhan pangan, serta melihat potensi yang dimiliki oleh masyarakat sekitar. Setelah itu, membuat Memorandum of Agreement (MoA) dengan mitra. Tahapan kedua adalah sosialisasi kegiatan terhadap masyarakat sekitar. Tujuan dari kegiatan ini adalah mengedukasi dan memotivasi masyarakat untuk mengembangkan dan memanfaatkan lahan yang dimiliki agar tepat guna. Upaya yang dilakukan meliputi: (1) pemberian motivasi tentang pemanfaatan lahan pekarangan; (2) penyuluhan tentang ketahanan pangan keluarga (KPK) dan strateginya; dan (3) pelatihan budidaya tanaman holtikutura.

Tahap ketiga adalah penyerahan bibit tanaman holtikultura kepada warga sekitar. Pengabdi akan dibantu oleh karang taruna untuk mendampingi dan mengevaluasi proses penanaman bibit tanaman holtikultura di halaman rumah masing-masing warga. Masyarakat diharapkan mampu memanfaatkan lahan pekarangan dengan bibit tanaman yang telah diberikan untuk meningkatkan ketahanan pangan keluarga.

Kondisi pandemi Covid-19 membuat tim pengabdi memikirkan berbagai cara yang dapat dilakukan agar kegiatan pengabdian ini berjalan sesuai dengan rencana. Protokol kesehatan yang ketat dan pembatasan kegiatan 
mengumpulkan masyarakat membuat kegiatan ini tidak dapat dilakukan secara langsung bertatap muka dengan masyarakat. Kegiatan sosialisasi, penyuluhan dan pelatihan dilakukan secara daring, dengan video yang dishare melalui group WhatsApp. Koordinasi dengan karang taruna dilakukan dengan zoom meeting.

\section{HASIL DAN PEMBAHASAN}

Tahap pertama adalah observasi. Observasi dilakukan dengan melihat kebutuhan masyarakat, serta melihat potensi tanaman yang dapat dikembangkan dengan lahan yang ada. Lahan yang ada pada dusun Sidorejo memiliki kondisi tanah dan air yang baik sehingga lahan tersebut mampu ditanami berbagai jenis tanaman. Holtikultura menjadi salah satu pilihan jenis tanaman yang memiliki potensi untuk dikembangkan pada lahan tersebut. Pemilihan ini berdasarkan kebutuhan masyarakat. Selain itu, holtikultura merupakan salah satu komoditi pertanian yang berpeluang untuk meningkatkan kesejahteraan masyarakat (Pitaloka, 2020). Masyarakat diharapkan mampu memanfaatkan lahan pekarangannya dengan menanam tanaman holtikultura dan mengambil hasilnya sehingga dapat meminimalis pengeluaran kebutuhan keluarga terkait pangan. Mereka tidak perlu lagi membeli sayur dan buah ke warung, tetapi hanya dengan memetik dari hasil kebun untuk memenuhi kebutuhan pangan sehari-hari.

Tahap kedua, sosialisasi terkait program kegiatan. Adapun langkahlangkah dalam sosialisasi program meliputi: (1) pemberian motivasi tentang pemanfaatan lahan pekarangan, (2) penyuluhan tentang Ketahanan Pangan Keluarga (KPK), dan (3) pelatihan budidaya tanaman holtikutura. Dengan kegiatan ini diharapkan kebutuhan pangan ditingkat keluarga dapat tercukup sehingga mampu mewujudkan penguatan Ketahanan Pangan Keluarga (KPK). Berikut ini adalah proses kegiatan penguatan Ketahanan Pangan Keluarga (KPK):

\section{Motivasi Tentang Pemanfaatan Lahan Pekarangan}

Kegiatan ini dimulai dengan sosialisasi lahan pekarangan. Sosialisasi dilakukan melalui video. Video dibuat oleh tim dengan melibatkan karang taruna sebagai penanggung jawab kebun bibit. Video yang dibuat disebarluaskan ke masyarakat melalui grup-grup media sosial yang ada di masyarakat dusun Sidorejo. Sosialisasi berlangsung selama dua minggu. Video sosialisasi ini berisi tentang pengenalan kebun bibit, tujuan dibuatnya kebun bibit, berbagai jenis bibit tanaman yang ada di kebun bibit dan kegiatan-kegiatan yang ada dikebun bibit. Kegiatan yang ada di kebun bibit antara lain pembibitan, penyemaian dan perawatan tanaman. Gambar 1 menunjukkan salah satu kegiatan penyemaian bibit. 


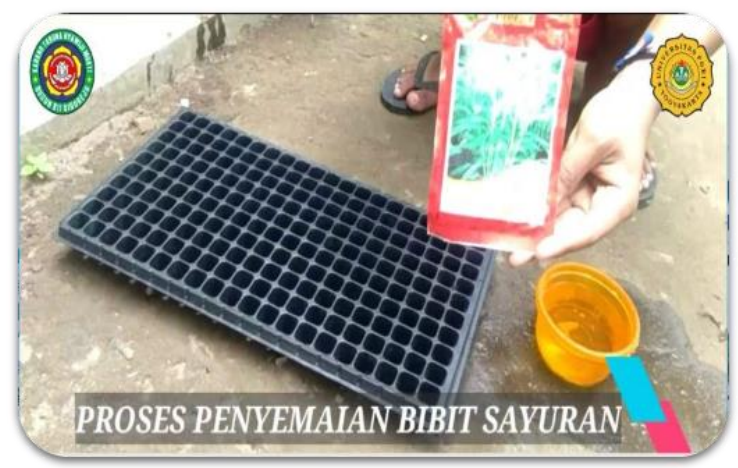

Gambar 1. Kegiatan penyemaian bibit

Pemberian motivasi dilakukan melalui video yang dibagikan. Di dalamnya terdapat contoh keberhasilan suatu wilayah dalam memanfaatkan lahan pekarangan untuk meningkatkan ketahanan pangan keluarga.

2. Penyuluhan Tentang Ketahanan Pangan Keluarga

Kegiatan penyuluhan dilakukan melalui penyebaran poster tentang ketahanan pangan keluarga. Poster dibuat berwarna dan dengan bahasa yang sederhana agar tampak menarik sehingga pesan di dalamnya dapat tersampaikan kepada masyarakat. Poster terdiri dari dua halaman. Contoh poster dapat dilihat pada Gambar 2 dan Gambar 3.

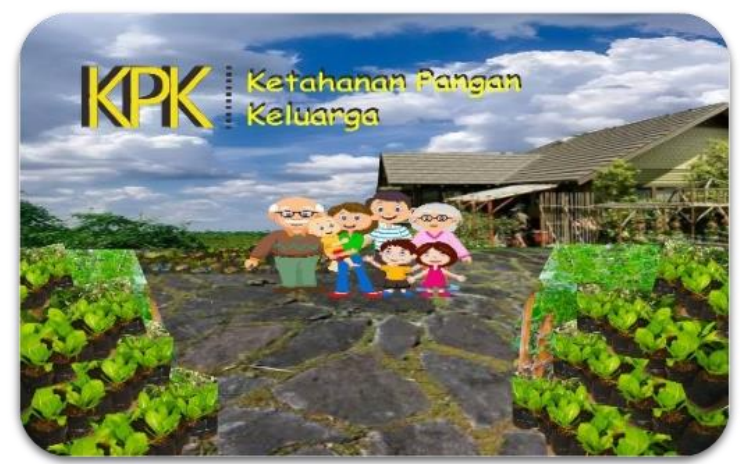

Gambar 2. Halaman depan poster 


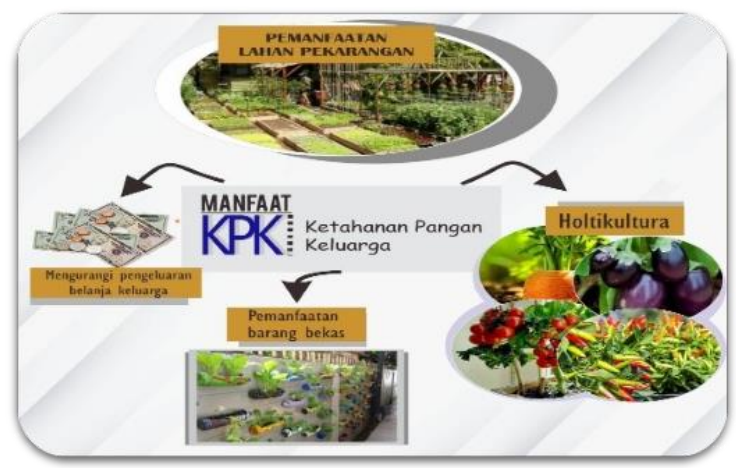

Gambar 3. Isi poster

3. Pelatihan Budidaya Tanaman Hortikultura

Pelatihan budidaya tanaman holtikultura dilakukan melalui video oleh para pengurus kebun bibit. Pelatihan diberikan mulai dari cara pembibitan, penyemaian sampai dengan perawatan tanaman. Kegiatan pelatihan dapat dilihat pada Gambar 4.

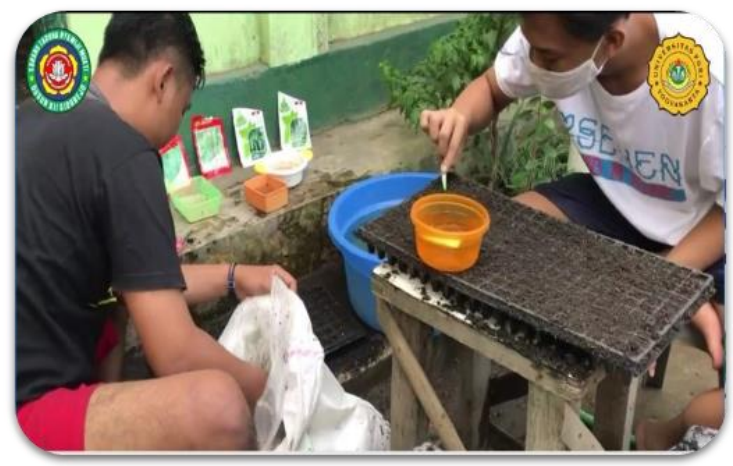

Gambar 4. Kegiatan pelatihan

Setelah dilakukan sosialisasi, penyuluhan, dan pelatihan, masyarakat diajak untuk melakukan penanaman tanaman hortikultura di lahan pekarangan masing-masing. Kegiatan yang dilakukan adalah penyerahan bibit tanaman kepada warga yang sudah siap untuk menanam. Pendampingan dilakukan oleh tim pengabdi dan beberapa karang taruna. Komunikasi pendampingan dilakukan secara langsung dengan tetap memperhatikan protokol Kesehatan, selain itu pendampingan juga dilakukan melalui WhatsApp (WA). Hal ini dilakukan karena adanya keterbatasan waktu dan tenaga serta memperhatikan situsi pandemi saat ini.

Kegiatan berlangsung kurang lebih selama 4 bulan. Tahap pertama sampai tahap terakhir berlangsung selama 1 bulan. Tiga bulan berikutnya adalah mengamati hasil dari kegiatan tersebut. Sebelum adanya kegiatan ini, hanya 2 kepala keluarga yang memanfaatkan lahan pekarangannya. Berdasarkan hasil observasi, terlihat bahwa jumlah warga yang menanam tanaman holtikultura mengalami peningkatan sebesar $75,38 \%$. Sedangkan 
respon masyarakat terhadap program ini sebesar $77,6 \%$. Hal ini berarti masyarakat di dusun Sidorejo sangat terbantu dengan adanya program ini. Mereka termotivasi dalam memanfaatkan maupun mengembangkan lahan yang dimiliki. Masyarakat lebih teredukasi untuk melakukan budidaya tanaman holtikultura.

Program tersebut diharapkan belangsung lama dan konsisten, sehingga mereka bisa memanfaatkan hasil panen dari pekarangan sendiri. Selain itu, diharapkan antar warga saling bisa bertukar hasil panen dari pekarangan mereka. Hal ini akan membuat masyarakat menjadi bersemangat untuk memanfaatkan lahan pekarangan mereka dalam mengembangkan tanaman holtikultura.

\section{KESIMPULAN}

Kegiatan ini terlaksana dengan baik. Jumlah warga yang menanam holtikultura mengalami peningkatan sebesar $75,38 \%$. Sedangkan hasil angket respon masyarakat terkait kegiatan ini menunjukkan respon yang baik dengan persentase sebesar $77,6 \%$. Hal ini berarti masyarakat di dusun Sidorejo sangat terbantu dengan adanya kegiatan ini. Mereka termotivasi dalam memanfaatkan maupun mengembangkan lahan yang dimiliki. Masyarakat lebih teredukasi untuk melakukan budidaya tanaman holtikultura.

Warga berharap agar kegiatan pengabdian dapat dilanjutkan dengan jenis kegiatan yang lain seperti pendampingan untuk mengembangkan kegiatan yang ada dikebun bibit. Dengan adanya pendampingan yang dilakukan secara berkesinambungan, diharapkan masyarakat di dusun Sidorejo akan lebih teredukasi untuk berkreasi dalam mengekspolitasi lahan yang mereka miliki.

\section{DAFTAR RUJUKAN}

Aisyah, I. S. (2020). Ketahanan Pangan Keluarga di Masa Pandemi Covid 19. Jurnal Kesehatan Komunitas Indonesia, 16(2), 179-189. http://jurnal.unsil.ac.id/index.php/jkki/article/view/2576

Alika, R. (2020). Tiga Bulan Pandemi, Kemenkeu Taksir Kerugian Ekonomi RI Rp 316 Triliun. Katadata.Com.

Arida, A., Sofyan, \& Fadhiela, K. (2015). Analisis Ketahanan Pangan Rumah Tangga Berdasarkan Proporsi Pengeluaran Pangan Dan Konsumsi Energi. Agrisep, 16(1), 20-34. https://doi.org/10.24815/agrisep.v16i1.3028

Ediwiyati, R., Koestiono, D., \& Setiawan, B. (2015). Analisis Ketahanan Pangan Rumah Tangga (Studi Kasus Pada Pelaksanaan Program Desa Mandiri Pangan di Desa Oro Bulu Kecamatan Rembang Kabupaten Pasuruan). Agrise, 15(2),

85-93. https://agrise.ub.ac.id/index.php/agrise/article/view/165

Fallis, A. . (2013). Tinjauan Pustaka Hortikultura. Journal of Chemical Information and Modeling, 53(9), 1689-1699. https://doi.org/10.1017/CBO9781107415324.004

Hadi, P. U., \& Susilowati, S. H. (2010). Prospek, Masalah Dan Strategi 
Pemenuhan Kebutuhan Pangan Pokok. In Prosiding Seminar Nasional Era Baru Pembangunan Pertanian: Strategi Mengatasi Masalah Pangan, Bio-Energi dan Perubahan Iklim (Vol. 1, Issue i, pp. 35-57).

Hadiwardoyo, W. (2020). Kerugian Ekonomi Nasional Akibat Pandemi Covid19. Baskara Journal of Business and Enterpreneurship, 2(2), 83-92. https://doi.org/10.24853/baskara.2.2.83-92

Hirawan, F. B., \& Verselita, A. A. (2020). Kebijakan Pangan di Masa Pandemi COVID-19. Centre for Strategic and International Studies. https://www.csis.or.id/publications/kebijakan-pangan-di-masa-pandemicovid-19

Masniadi, R., Angkasa, M. A. Z., Karmeli, E., \& Esabella, S. (2020). Telaah kritis ketahanan pangan Kabupaten Sumbawa dalam menghadapi pandemi covid-19. Indonesian Journal of Social Sciences and Humanities (IJSSH), 1(2), 109-120. https://journal.publicationcenter.com/index.php/ijssh/article/view/111

Nasution, D. A. D., Erlina, E., \& Muda, I. (2020). Dampak Pandemi COVID-19 terhadap Perekonomian Indonesia. Jurnal Benefita, 5(2), 212. https://doi.org/10.22216/jbe.v5i2.5313

Pitaloka, D. (2020). Hortikultura: Potensi, Pengembangan Dan Tantangan. Jurnal Teknologi Terapan: G-Tech, 1(1), 1-4. https://doi.org/10.33379/gtech.v1i1.260

Rahmawati, E. (2012). Aspek Distribusi pada Ketahanan Pangan Masyarakat di Kabupaten Tapin. 02(September).

Sakharina, I. K. (2020). Hak Atas Pangan di Masa Pandemi Coronavirus Disease Covid-19. Jurnal Legislatif, 3(2), 367-384. https://journal.unhas.ac.id/index.php/jhl/article/view/10476

Saliem, H. P., \& Ariani, M. (2016). Ketahanan Pangan, Konsep, Pengukuran dan Strategi. Forum Penelitian Agro Ekonomi, 20(1), 12. https://doi.org/10.21082/fae.v20n1.2002.12-24

UMY. (2020). Ketahanan Pangan Indonesia di Masa Pandemi / Universitas Muhammadiyah Yogyakarta.

Wahyono, E. (2020). Kapan Sebenarnya Corona Pertama Kali Masuk RI? In Detik.Com (p. 1). 